\title{
DESIGN TIPOGRÁFICO HEBRAICO: um aparente paradoxo entre simplicidade e complexidade
}

\section{HEBREW TYPEFACE DESIGN: an apparent paradox between simplicity and complexity}

\author{
Sérgio Luciano da Silva \\ Universidade do Estado de Minas Gerais \\ sergiolucianosilva@gmail.com
}

\begin{abstract}
Resumo: Este artigo, apoiado nos estudos dos historiadores Richard Goerwitz e John Man e nas pesquisas dos especialistas em tipografia Ada Yardeni, Misha Beletsky e Yannis Haralambous, procede a uma análise diacrônica da escrita hebraica, com ênfase na história da tipografia e na cultura, em sua conexão com os rumos do mercado internacional de produção de fontes tipográficas. A partir da solução de um aparente paradoxo associado às características do hebraico, procura sintetizar e estabelecer critérios que regem essa escrita em sua forma tipográfica atual. O objetivo e contribuição principal deste trabalho são avançar sobre a formação de uma dinâmica metodológica que regula o design tipográfico multiescrita, indo além das fronteiras dos alfabetos, e subsidiar os designers com fundamentos do hebraico que estão formal e culturalmente mais distantes da tipografia ocidental.
\end{abstract}

Palavras-chave: Design tipográfico, Design de faces hebraicas, Tipografia multiescrita, História da tipografia.

\begin{abstract}
This paper, based on the studies of the historians Richard Goerwitz and John Man and on the researches of the typography specialists Ada Yardeni, Misha Beletsky, and Yannis Haralambous, proceeds to a diachronic analysis of the Hebrew script, with emphasis on the history of typography and on culture, also regarding its connection with the international market for the production of typographic fonts. From the solution of an apparent paradox associated with features of Hebrew script, this paper synthesizes and establishes criteria that rule this script in its present typographic form. Moreover, the aim of this work is to improve the methodological dynamics that regulates multi-script typeface design, going beyond the boundaries of alphabets, and its main contribution is to provide foundation to the designers with Hebrew grounds that are formally and culturally distant from Western typography.
\end{abstract}

Keywords: Typeface design, Hebrew typeface design, Multi-script typography, History of typography. 


\section{INTRODUÇÃO - CONVICÇÕES E HIPÓTESES}

Este artigo deriva de nossas pesquisas sobre o tema do design tipográfico em mais de uma escrita, especialmente nos artigos (SILVA; LANA; SILVA, 2010), (SILVA; SILVA, 2010), (SILVA; SILVA; LANA, 2011) e (SILVA, 2013) e como consequência natural vai além do território dos alfabetos. Nos trabalhos anteriores a questão sobre a inclusão de uma escrita não alfabética como o hebraico em um projeto multiescrita é abordada de modo pontual, em contraposição a três escritas alfabéticas: a latina, a grega e a cirílica. Aqui, nosso objeto central é o design tipográfico hebraico. Porém, é importante destacar que a especificidade e recorte deste estudo estão em buscar a compreensão dos critérios e fundamentos tipográficos dessa escrita não somente no âmbito de sua produção doméstica, como ocorre em alguns estudos (BELETSKY, 2002), (HARALAMBOUS, 1994), (TOLEDO; ROSENBERG, 2003) e (YARDENI, 2002), mas também no território do mercado internacional de criação de faces de tipo e de produção de fontes. Como resultado da escolha dessa abordagem, as análises empreendidas a seguir pressupõem a relação da escrita hebraica com aquelas que regular ${ }^{1}$ e preferencialmente a acompanham em fontes multiescrita, ou seja, a latina, a grega e a cirílica.

Esta abordagem parte de uma análise diacrônica, buscando a compreensão de aspectos histórico-culturais e formais da escrita hebraica, identificando e extraindo quais características da mesma são mais relevantes para o design tipográfico, um campo que cada vez mais reúne escritas com características distintas. Em primeiro lugar, por trás deste procedimento está a convicção de que a escrita, enquanto "forma sólida da linguagem" (BRINGHURST, 2006), constituiu-se primordialmente a partir dos povos que passaram a utilizá-la em função de suas necessidades, fossem elas quais fossem ${ }^{2}$. Em segundo, está a hipótese de trabalho de que é possível extrair de tais análises critérios metodológicos que possam ser compartilhados com aqueles já estabelecidos para os alfabetos latino, grego e cirílico em projetos que abranjam essas quatro escritas.

\section{DELIMITAÇÃO DO PROBLEMA: ESCAPANDO A UM APARENTE PARADOXO E REINTRODUZINDO O CRITÉRIO DE PROXIMIDADE}

O tema do artigo atual ultrapassa o território mais próximo, para os designers ocidentais, dos alfabetos ${ }^{3}$, e amplia o estudo para os abjads ${ }^{4}$, especificamente o hebraico. Se a pesquisa atual amplia o escopo de atuação, é importante destacar que este caminho, na verdade, mantém relação com o Critério de Proximidade que determinamos anteriormente. Vejamos o que caracteriza tal critério e como a relação se preserva.

\footnotetext{
${ }^{1} A$ regularidade e frequência encontrada na produção de fontes que incluem, além da escrita latina, cirílica e grega, também a hebraica foi analisada anteriormente (SILVA; SILVA; LANA, 2011). Segundo nosso entendimento, a relevância do hebraico para justificar sua inserção em projetos multiescrita se deve principalmente ao fato de que essa escrita (mesmo sendo utilizada por um número muito menor de pessoas, se comparada com a latina ou a cirílica) tem difusão mundial nas diversas comunidades judaicas espalhadas pelo planeta.

2 O historiador John Man (2002) considera, por exemplo, que os gregos, ao contrário do que pressupõem classicistas como Erick Havelock (1994), constituíram sua escrita não a partir de aspirações culturais de uma elite, mas da necessidade do registro de atividades comerciais e de controle das práticas de trabalho.

${ }^{3} \mathrm{O}$ alfabeto é um sistema de escrita formado por letras, tanto consoantes quanto vogais, que partilham igual privilégio na constituição de sua estrutura. (DANIELS, 1996), (UNICODE, 2011)

${ }^{4} \mathrm{O}$ termo abjad tem origem nas quatro primeiras letras da escrita arábica (alef, beh, jeem e dal). Uma das característicos distintivas dos abjads em relação aos alfabetos é que suas letras são consoantes ou vogais longas, tendo suas vogais excluídas ou indicadas apenas por sinais diacríticos nas consoantes. Exemplos de abjad são as escritas arábica e hebraica. (DANIELS, 1996), (UNICODE, 2011)
} 
O Critério de Proximidade é um dos parâmetros de escolha de escritas que estabelecemos para projetos iniciantes e diz respeito à facilidade e intimidade que os designers tipográficos têm com escritas mais próximas de sua cultura: "é muito mais simples para um designer que tem como escrita nativa o alfabeto latino criar faces em escritas também alfabéticas, como o grego e o cirílico [...], do que em abjads, como o hebraico ou o arábico" (SILVA; SILVA; LANA, 2011, p. 5). A obviedade de tal critério não deve, no entanto, ser subestimada. Se tal preceito for aplicado sem imersão nas culturas e compreensão da história e das origens das escritas envolvidas pode levarnos a aparentes contradições e aporias.

Analisemos o caso específico do hebraico. Com exemplos apenas de duas características dessa escrita, como a inexistência das formas maiúsculas e minúsculas e a substituição de vogais por sinais diacríticos acoplados às consoantes, percebemos a distância estrutural que a separa dos alfabetos. Porém, mais do que isso, refletindo um pouco sobre essas duas características pode parecer, para o olhar de um designer ocidental, que o antagonismo desses aspectos conduz a uma espécie de paradoxo entre elementos simples e complexos da escrita hebraica: de um lado a simplicidade de uma forma única de letras comparadas à estrutura de letras bicamerais ocidentais e de outro, a complexidade na construção e aplicação de vogais em relação ao modelo alfabético.

No entanto, se procuramos nos situar no universo exclusivo da cultura, língua e escrita hebraicas, como ocorre nas pesquisas de Ada Yardeni (2002), Misha Beletsky (2002), Sivan Toledo e Zvika Rosenberg (2003), a contradição desaparece. Para designers israelenses e de origem judaica, que tem compreensão e vivência de sua escrita nativa, não existem características distintivas mais simples ou mais complexas contradizendo umas às outras, a não ser que seus projetos abarquem outras escritas além da hebraica. $E$, neste ponto, chegamos ao cerne da questão. É justamente quando se unem num mesmo projeto escritas com características distintas, e o designer se vê desafiado a criar faces de tipo que preservem de um lado a identidade de cada escrita e de outro a harmonia entre elas, que possíveis contradições aparecem. Assim, é no domínio da multiescrita, ao sairmos do confortável e estrito âmbito do design em apenas uma escrita e a confrontarmos no diálogo com outras, que o paradoxo pode ressurgir.

Para superarmos tal questão inicial nossa hipótese é de que, neste caso, diferentemente de um paradoxo, os aspectos simples não contradizem os complexos. Assim, é necessário mantermos um duplo esforço de atenção: àquilo que estrutura a escrita hebraica em sua forma nativa e também às suas relações históricas e culturais com os alfabetos. Neste sentido, uma breve análise diacrônica sobre a constituição de algumas escritas, a seguir, torna mais evidente tanto as intrincadas conexões entre essas escritas quanto o grau de proximidade ou distanciamento cultural delas ao longo de seu desenvolvimento histórico.

Observe na Figura 1 a linha do tempo de alguns abjads e alfabetos. Os abjads, por não conterem vogais explícitas, estabelecem as suas estruturas mínimas como letras consoantes, correlatas às consoantes dos alfabetos. Para o design tipográfico, não só do ponto de vista histórico, é relevante o fato de que o alfabeto grego (que originou 0 etrusco, o latino e o cirílico) nasceu de um abjad quando os gregos alteraram a escrita fenícia abjadca para criar a sua. Igualmente importante é que esse mesmo abjad tenha originado tanto alfabetos quanto outros abjads. Assim, apesar das consideráveis diferenças que separam abjads e alfabetos na atualidade, a sua origem comum bem como similaridades estruturais não podem ser desprezadas, principalmente se compararmos 
estes dois sistemas de escrita a outros com características mais distintas como os silabários, os abugidas e os logossilabários. (UNICODE, 2011, p. 178-181)

Figura 1 - Linha do tempo com origem de parte dos alfabetos e abjads.

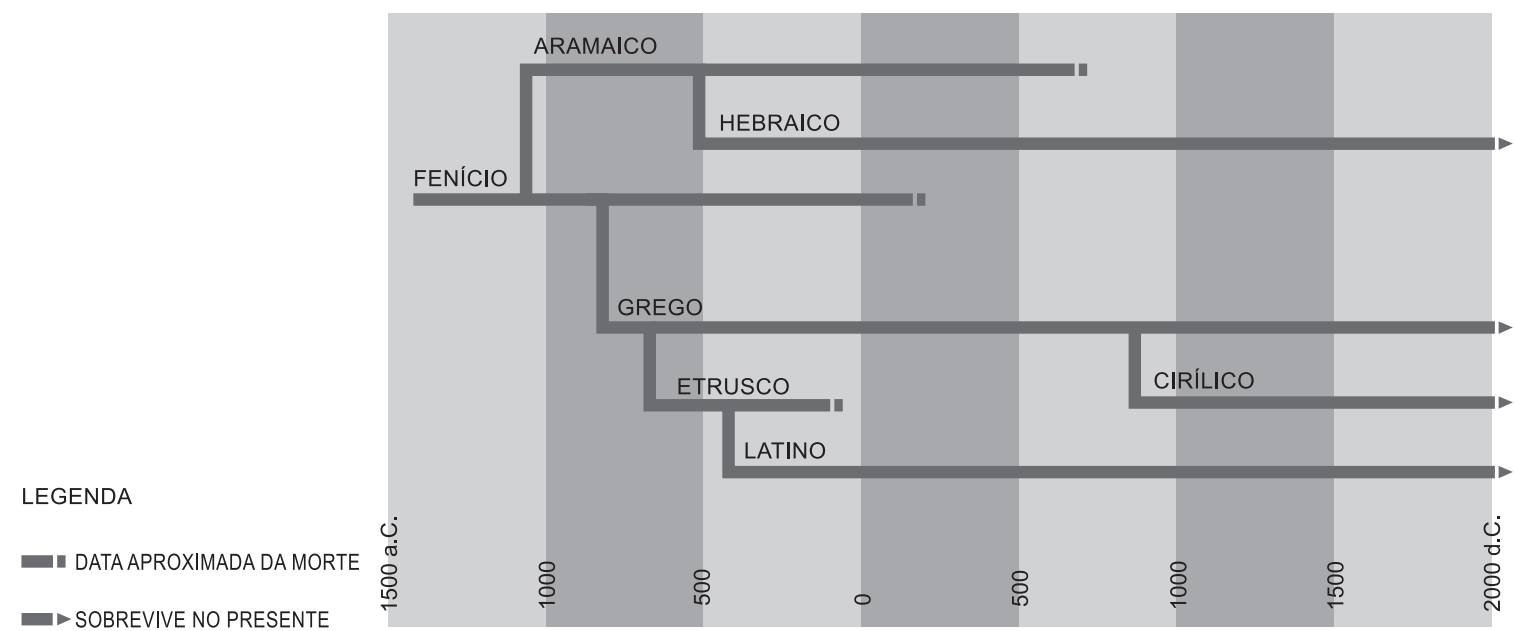

Fonte: Elaborado pelo autor, baseado em John Man (2002).

Com essa "árvore genealógica" minimamente estabelecida, é necessário extrair da análise do hebraico as características mais simples e em seguida as mais complexas em busca da síntese de critérios para o design tipográfico deste abjad inserido no universo multiescrita.

\section{IDENTIFICANDO E SE BENEFICIANDO DA SIMPLICIDADE}

A escrita hebraica antiga foi provavelmente herdada dos fenícios (GOEERWITZ, 1996), mas posteriormente substituída pela aramaica, também um abjad como o fenício. O hebraico moderno (descendente do aramaico) divide-se em três ramos: o cursivo, empregado cotidianamente, o rabínico, para comentários dos rabinos, e o meruba (quadrado), para uso formal em livros (Figura 2). É esta terceira forma que foi mais aplicada como referência na impressa, para a produção de fontes tipográficas ao longo dos últimos cinco séculos.

Figura 2 - Os três ramos da escrita hebraica moderna.

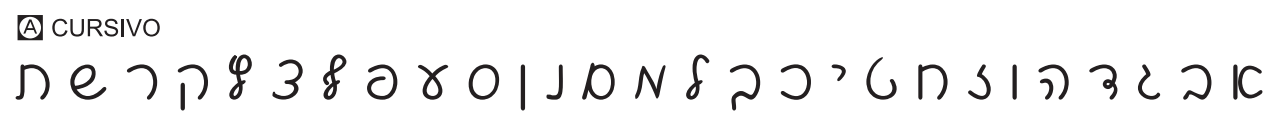

Fonte: Elaborado pelo autor, com base na pesquisa realizada. 
Atualmente a forma meruba está consolidada em Israel para uso nos diversos meios de comunicação e tem um crescente número de fontes tipográficas disponíveis para aplicação formal e informal (TOLEDO; ROSENBERG, 2003).

Para o designer ocidental, mais familiarizado com estruturas de escritas alfabéticas, o projeto de uma face de tipo e a produção de uma fonte tipográfica que incorpore um abjad, a princípio, preocupa. Mas, a despeito das dificuldades reais, o hebraico (estilo meruba) tem algumas características que simplificam o processo de criação:

1 Diferentemente dos alfabetos latino e grego, no abjad hebraico não existem as formas maiúsculas e minúsculas, mas apenas uma única forma de letras. Esta propriedade faz cair para a metade o número de letras a serem criadas, com a consequente redução de trabalho em todas as etapas.

20 abjad hebraico tem somente 22 letras (consoantes e vogais longas, conforme a Figura 3). Suas vogais curtas são indicadas com sinais diacríticos que se distribuem em três posições: em cima, no meio e embaixo das letras (Figura 4). No entanto, se a fonte for produzida para uso em jornais, revistas e livros não religiosos, sua estrutura pode ser simplificada. Isto porque, no uso cotidiano, as consoantes não precisam ser marcadas e, consequentemente, o designer não necessita incorporar à sua fonte grande quantidade de pares de crenagem para o posicionamento dos sinais diacríticos.

3 A forma geral de suas letras (que mudaram pouco nos últimos 2000 anos) facilita tanto a pesquisa baseada em referências históricas e caligráficas quanto o desenho e o espaçamento básico dos glifos.

Figura 3 - Abjad hebraico: as letras marcadas em cinza-claro têm duas diferentes formas. A segunda forma (cinza-escuro) é para o final das palavras.

\begin{tabular}{|c|c|c|c|c|c|}
\hline LETRA & NOME & LETRA & NOME & LETRA & NOME \\
\hline $\boldsymbol{X}$ & ALEF & ) & YOD & $y$ & AYIN \\
\hline-1 & BET & & KAF & 9 & PE \\
\hline$\lambda$ & GIMEL & & FINAL KAF & 7 & FINAL PE \\
\hline$T$ & DALET & & LAMED & 4 & TSADI \\
\hline 7 & HE & מ & MEM & $Y$ & FINAL TSADI \\
\hline 1 & VAV & $\square$ & FINAL MEM & $P$ & QOF \\
\hline$r$ & ZAYIN & $J$ & NUN & 4 & RESH \\
\hline$n$ & HET & & FINAL NUN & $\mathcal{U}$ & SHIN \\
\hline 0 & TET & 0 & SAMEKH & ת & TAV \\
\hline
\end{tabular}

Fonte: Elaborado pelo autor, com base na pesquisa realizada. 
Figura 4 - As letras da esquerda contém os eixos de simetria para orientar a inserção de diacríticos. As letras da direita incluem os sinais aplicados nas posições corretas.

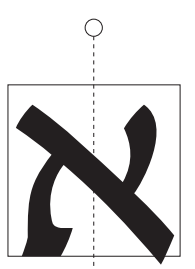

$\circ$

0

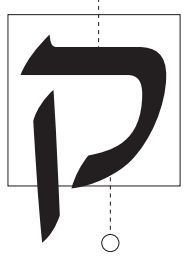

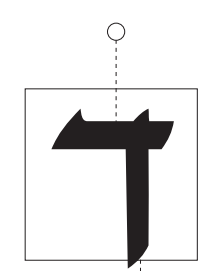

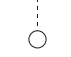

0

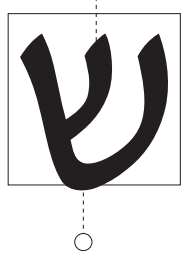

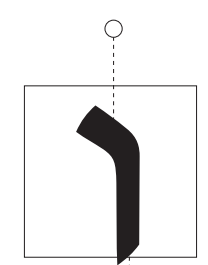

○่

○

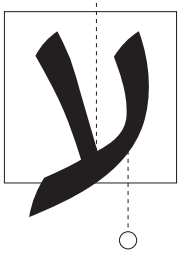

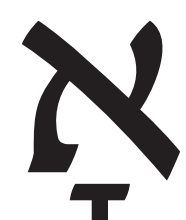
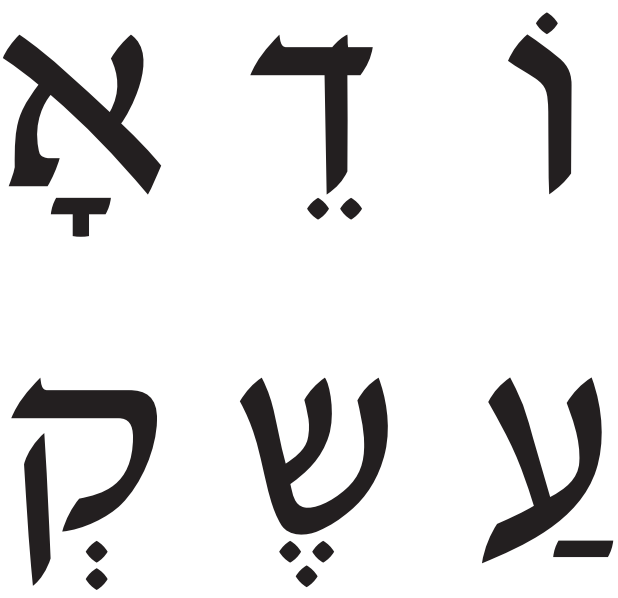

Fonte: Elaborado pelo autor, com base em Yannis Haralambous (1994).

\section{FUNDAMENTOS HISTÓRICOS E CULTURAIS}

Como vimos, sendo um abjad, o hebraico está mais afastado conceitualmente e culturalmente dos alfabetos latino e grego. Assim, aos critérios de pesquisa histórica e conhecimento das estruturas caligráficas de uma escrita, já estabelecidos (SILVA; SILVA, 2010), deve-se somar a necessidade de estudo, mesmo que básico, do idioma em questão. Dados sobre a história do povo judeu, da sua escrita e língua, ou como afirma Ada Yardeni (2002, p. 307) "o fator histórico", completam os elementos para o entendimento dos fundamentos específicos desse abjad e por consequência de sua tipografia. A relevância deste fator não deve ser menosprezada.

O primeiro elemento histórico diz respeito ao exílio e à dispersão da nação judaica pelo mundo, por mais de dois mil anos. A diáspora impôs sérias dificuldades à manutenção da integridade de sua cultura. Se por um lado as perseguições e expulsões não conseguiram eliminar suas crenças e valores, por outro, dificultaram o estabelecimento de bases sólidas para uma produção tipográfica contínua, que possibilitasse uma evolução ininterrupta dos seus modelos e estilos de faces de tipo. Ora, como qualquer outra atividade livre e complexa, para que a imprensa possa prosperar são necessárias condições mínimas de estabilidade política e liberdade civil, que a suportem a longo prazo. Exemplo disto é o da impressa grega, que só se instituiu após a retomada de seu país das mãos do Império Otomano. E de modo análogo à tipografia grega, que até 1821 foi impulsionada em grande parte por profissionais estrangeiros, trabalhando fora da Grécia, parte apreciável daqueles que contribuíram de modo significativo para a tipografia hebraica (também até o século XIX) não eram judeus $^{5}$ (BELETSKY; 2002, p. 94). Destacam-se entre eles o editor Daniel Bomberg (?1549), o impressor Christopher Plantin (1520-89) os puncionistas Francesco Griffo (c. 1450-1518), Robert Granjon (c. 1513-90), Guillaume Le Bé (1525-98) e Christoffel van Dijck (1606-69), na virada do século XVI para o século XVII.

\footnotetext{
${ }^{5}$ Judeus como o editor Gershom Soncino e impressores como Abraham Conat, Meshullam Cusi, Joseph Gunzenhauser entre outros, compõem também o quadro de profissionais que atuaram na constituição da imprensa hebraica.
} 
No século XVIII não ocorreram grandes mudanças nas formas das faces hebraicas. Algumas alterações feitas foram baseadas nas faces latinas de Giambattista Bodoni (1740-1813), com consequente exagero nas diferenças de espessura entre linhas horizontais e verticais das letras. O século XIX foi um período de poucas criações de faces hebraicas. No entanto, na passagem do século XIX para o XX o professor, designer e tipógrafo judeu alemão Rafael Frank (1867-1920) desempenhou um relevante papel para a evolução da tipografia hebraica. Conforme afirma Misha Beletsky (2002, p. 96), a face Frank Rühl, criada por Rafael Frank, supera uma série de limitações, como o alto contraste que reduzia a legibilidade das faces anteriores. No século XX, a cidade de Weimar, na Alemanha, tornou-se um centro de design de faces e publicação de livros hebraicos. Judeus alemães, envolvidos profissionalmente com tipografia, levaram para Israel seus conhecimentos e experiências quando este Estado se constituiu em 1948. Outros designers (alguns dos quais não vivendo em Israel) têm contribuído para o desenvolvimento e aprimoramento da escrita hebraica em sua forma tipográfica. Entre eles se destacam Henri Friedlaender (1904-1996), Eliahu Koren (1909-2001), Ismar David (1910-1996) e Zvi Narkiss (1921-2010).

Um segundo elemento histórico e cultural relevante se relaciona à constituição das duas maiores comunidades judaicas na Europa, a Asquenaze, na Alemanha e norte da França, e a Sefardi, na Espanha e Portugal. Foram principalmente os dois estilos de escrita desenvolvidos nessas comunidades que mais influenciaram a produção tipográfica hebraica na sua instauração, sendo, desde então, referência para o design tipográfico. A Figura 5 apresenta trechos de dois manuscritos em Asquenaze e Sefardi. Note como o Asquenaze, à esquerda, tem formas losangulares e um caráter mais decorativo, com alto contraste entre os traços, uma linha de base bem marcada, mas com as partes internas das letras estreitas. Já no Sefardi, à direita, as letras não se apoiam tão firmemente na linha de base, porém suas partes internas são amplas, o que aumenta a legibilidade. Historicamente, com o advento da imprensa, o estilo caligráfico Sefardi prevaleceu sobre o Asquenaze, mas algumas estruturas formais próprias ao Asquenaze ainda são exploradas pelos designers na criação de faces. Na Figura 6 as letras Shin e Tet, à esquerda, têm formas curvas na sua parte inferior, típicas do estilo Asquenaze e as mesmas letras, à direita, têm formas em arestas no estilo Sefardi.

Figura 5 - Trechos de manuscritos hebraicos: à esquerda, fac-símile do Haggadah de Páscoa (1333) em Asquenaze e, à direita, da Bíblia hebraica em Sefardi (1344).
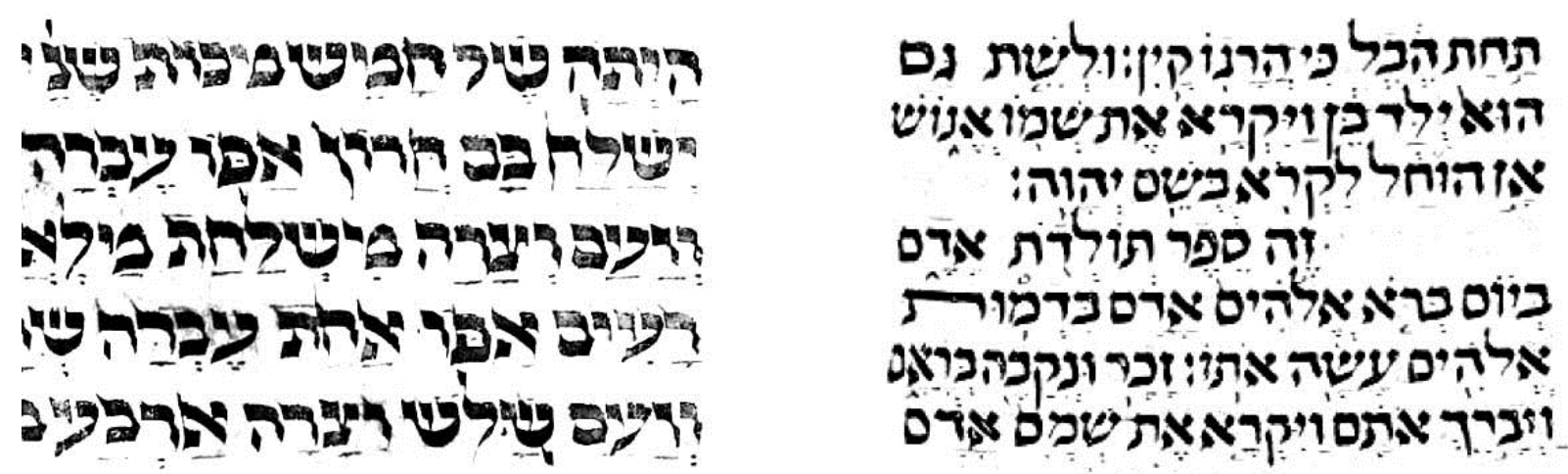

Fonte: GALLICA - Bibliotèque Numerique <gallica.bnf.fr> 
Figura 6 - À esquerda, letras hebraicas Shin e Tet (fonte CTAN Nach) com curvas em Asquenazi e à direita as mesmas letras (fonte CTAN David) em Sefardi.

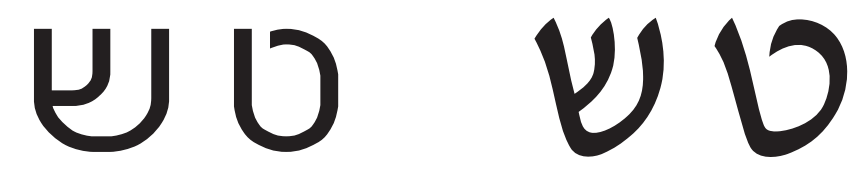

Fonte: Elaborado pelo autor, com base na pesquisa realizada.

\section{ORGANIZANDO E EXPLORANDO A COMPLEXIDADE}

De posse dos fundamentos históricos e culturais intrínsecos à escrita e tipografia hebraica, acreditamos que podemos enfrentar o desafio de projetos que incluem o hebraico desde que nos guiemos por uma metodologia que explore conscientemente a complexidade da união de conceitos diversos. Por trás dessa decisão estão critérios e procedimentos (que já nos orientam em relação a escritas como o grego e o cirílico) em que a identificação e a classificação daquilo que é complexo são etapas essenciais para a apropriação e domínio de uma escrita em seu âmbito tipográfico. Deste modo, algumas características distintivas, em relação ao que estamos habituados no Ocidente, devem ser observadas quando da criação de uma face de tipo que inclua a escrita hebraica:

1 A escrita hebraica, numa página, segue o caminho inverso da latina, isto é, processa-se da direita para a esquerda. Isto influencia tanto os traços caligráficos - ângulos na ponta da caneta, posição e deslocamento da mão, configuração dos ductos - (LALOU, 2004), quanto o desenho das faces de tipo, que de alguma maneira são derivadas destas formas de traços.

2 Não se pode falar, num sentido estrito, das denominações estilísticas de serifa e sem serifa (aplicáveis às tipografias latina em sua origem e grega e cirílica por assimilação), e que não tem correspondência direta com a tipografia hebraica. Faces com um maior contraste grosso/fino podem, num sentido mais distendido, serem identificadas com as serifadas (item A da Figura 7, face Ezra $\mathrm{SIL}$ ). Já as faces com pouca ou nenhuma modulação nos traços (item $D$ e item $E$ da Figura 7, face CTAN Nach) aproximam-se de suas correspondentes sem serifa da tipografia latina. Estas identificações permitem a criação de faces que incorporem a escrita latina, a grega, a cirílica e a hebraica em um mesmo projeto, buscando manter unidade visual e harmonia entre as mesmas. Mas devem ser sempre observadas as diferenças conceituais existentes entre cada escrita e a tipografia derivada delas.

3 Os estilos Asquenaze e Sefardi se fazem presentes nas faces de tipo da atualidade. Portanto, é importante aprofundar o conhecimento de suas características para aproveitar a carga histórica e caligráfica que os mesmos trazem. Assim, a consulta a manuscritos e livros clássicos impressos em hebraico bem como o estudo de obras sobre paleografia e caligrafia devem de preferência subsidiar estes dois fundamentos. 
Como acontece com algumas letras da escrita grega, existem cinco letras da hebraica (Kaf, Mem, Nun, Pe e Tsadi ) que têm uma segunda forma, quando aparecem ao final das palavras (itens cinza-escuro da Figura 3). Cabe ao designer criar e incluir cada uma delas nos arquivos da fonte. Atualmente, com a capacidade intrínseca das tecnologias OpenType e Unicode e o recurso de substituição dinâmica de glifos, previsto também para este tipo de ocorrência, a tarefa deste tipo de produção está documentada. (TOLEDO; ROSENBERG, 2003)

5 Uma estrutura de crenagem que suporte a combinação dos sinais diacríticos (representantes das vogais) com as demais letras consoantes.

As características da lista anterior ampliam a tarefa do designer tanto no número de etapas a serem executadas quanto no nível de detalhamento de cada uma delas. Particularmente o processo de crenagem (item cinco da lista anterior) deverá ser mais minucioso caso pretenda-se produzir uma fonte tipográfica capaz de atender a publicações com um maior nível de exigência formal. Este é o caso quando se trata da edição de textos como os da Bíblia, de poesia e de livros infantis. Para este tipo de obra é necessário que a escrita mantenha o máximo de fidelidade semântica, eliminando as possibilidades de conteúdo ambíguo. Neste caso, os sinais diacríticos que indicam as vogais devem ser incluídos no projeto (Figura 4). Para ser capaz deste tipo de tarefa é preciso uma fonte com uma adequada estrutura de posicionamento entre os sinais diacríticos e as demais letras consoantes. No entanto, correlacionar letras e sinais, definir espaços e distâncias, fazer o ajuste fino entre os mesmos e incorporá-los à fonte, além de complexo demanda mais tempo. Assim, é fundamental desde o início de um projeto ter em mente para quais tipos de aplicação estará voltada uma fonte que inclui o hebraico.

Figura 7 - Faces com traços contrastantes podem ser associadas ao estilo serifado ocidental, e as de menor contraste (monoline) assemelham-se às sem serifa.

ब Ezra SIL

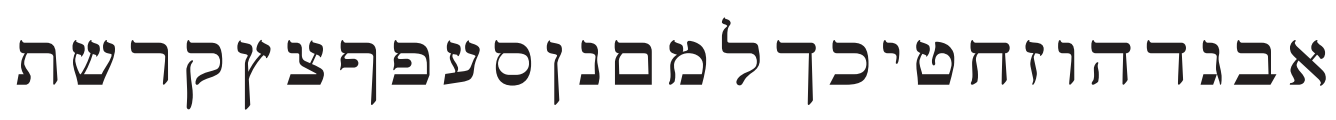

B] CTAN David Regular

\title{
אבגדהוזחטיכדלמםנןסעפףצץקרשת
}

C CTAN David Bold

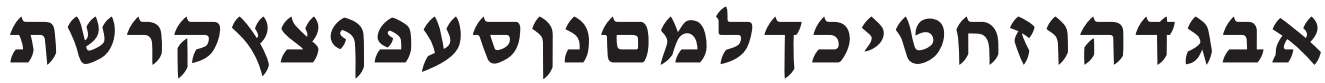

\author{
(D) CTAN Nachlight \\ אבגדהוזחטיכךלמםנןסעפףצץ
}

[E] CTAN Nachbold

\section{אבגדהוזחטיכךלמםנןסעפףצץ}

Fonte: Elaborado pelo autor, com base na pesquisa realizada. 


\section{CONSIDERAÇÕES FINAIS}

Não é novidade o fato de empresas de grande porte como Adobe, Apple, Microsoft, Nokia entre outras, investirem na produção de fontes com suporte a várias escritas. A atuação no mercado internacional (com softwares aplicativos voltados para a comunicação escrita) impõe naturalmente a essas empresas a oferta de produtos da categoria multiescrita. Mas o investimento por parte de produtoras de fontes e designers independentes ainda tem muito para avançar na tipografia hebraica. Como vimos, esta escrita, em sua forma tipográfica, não teve um desenvolvimento linear e estável como ocorreu com a latina. No entanto, os diversos obstáculos pelos quais passou, ou ainda passa, não devem ser encarados como limitação ao trabalho do designer tipográfico. $\mathrm{O}$ designer Misha Beletsky é enfático a esse respeito. Nas primeiras palavras do artigo em que esse autor faz uma análise de diversas faces hebraicas fica clara sua percepção de que há ainda muito por fazer neste campo a ser explorado:

Um especial desafio que o designer contemporâneo enfrenta, ao trabalhar com o hebraico, é a falta de um modelo claramente definido. Esta escrita nunca se formalizou como um estilo lapidar na forma como ocorreu com o alfabeto latino. Além disso, poucos projetos tipográficos históricos hebraicos foram bem-sucedidos o suficiente para merecer um revival. O designer tipográfico é, por conseguinte, em certo grau um inventor da escrita: ele decide qual das formas alternativas de letra usar, e assim, se o projeto é bem-sucedido, quais das formas irão tornar-se padrão ${ }^{6}$. (BELETSKY, 2002, p. 91)

Ada Yardeni corrobora a posição de Beletsky com argumentos semelhantes:

(...) qual é o propósito de projetar um novo estilo quando várias fontes e faces de tipo hebraicas já estão disponíveis para impressão e artes gráficas? Podemos responder que, de fato, o número destas fontes é relativamente pequeno e a maior parte delas têm sido concebidas com base no tipos Sefardi ou Asquenazi, juntamente com uma certa influência dos estilos latinos ${ }^{7}$. (YARDENI, 2002, p. 307)

As afirmações de Beletsky e Yardeni são um estímulo não somente para aqueles que pesquisam, mas também para os interessados na produção de fontes em hebraico. Mas as assertivas de ambos estão voltadas para a produção de fontes para o mercado interno de escrita hebraica. Isto não significa que não podemos correlacionar essas reflexões com projetos que ultrapassam as fronteiras do hebraico. Ora, do nosso ponto de vista, os critérios metodológicos que subsidiam o design em multiescrita compartilham parte de seus fundamentos com os de uma única escrita. Neste sentido, tanto a exploração consciente das carências e possibilidades inerentes às mesmas, quanto a atenção às demandas e aos rumos do mercado são relevantes no processo de criação. Em outras palavras, se as limitações e as lacunas apontadas são campos férteis para o processo criativo e expansão do design tipográfico hebraico, no nosso entendimento não existe razão para não aproveitar tais estímulos em projetos de fontes para o mercado multiescrita.

\footnotetext{
${ }^{6}$ Tradução nossa.

${ }^{7}$ Tradução nossa.
} 


\section{AGRADECIMENTOS}

$O$ autor agradece a:

- Fundação de Amparo à Pesquisa do Estado de Minas Gerais (FAPEMIG) pelo apoio financeiro.

- CTAN: Comprehensive $T_{E} X$ Archive Network <ctan.org>, pela distribuição gratuita das fontes CTAN David, projeto tipográfico de Maxim lorsh baseado na face David, de Ismar David, e CTAN Nach, também de Maxim lorsh.

- GALLICA: Bibliotèque Numerique <gallica.bnf.fr>, pelas imagens de distribuição gratuita dos manuscritos dos quais trechos ilustram a Figura 5.

- SIL: Summer Institute of Linguistics, Inc. <sil.org>, pela distribuição gratuita da fonte Ezra SIL, projeto tipográfico do grupo NRST (Non-Roman Script Initiative Team), com tabelas OpenType de Ralph Hancock.

\section{REFERÊNCIAS}

BELETSKY, Misha. Zvi Narkiss and Hebrew type design. In: BERRY, John D. (Org.). Language Culture Type: international type design in the age of Unicode. New York: ATypl \& Graphis, 2002. p. 91-106.

BRINGHURST, Robert. A forma sólida da linguagem: um ensaio sobre escrita e significado. Tradução Juliana A. Saad . São Paulo: Editora Rosari, 2006. 85 p.

DANIELS, Peter T. et al. The World's Writing Systems. New York: Oxford University Press, 1996. $968 \mathrm{p}$.

GOEERWITZ, Richard. The Jewish Scripts. In: Daniels, Peter T. et al. The World's Writing Systems. New York: Oxford University Press, 1996. p. 487-498.

HARALAMBOUS, Yannis. Typesetting the Holy Bible in Hebrew, with $T_{E} X$. 1994. 18 p. TUGboat - The Communications of the TeX Users Group - 15:3, September 1994. Disponível em:<http://www.tug.org/TUGboat/tb15-3/tb44haralambous-hebrew.pdf> Acesso em: 03 mar. 2012.

HAVELOCK, A. Eric. A revolução da escrita na Grécia e suas consequências culturais. Tradução. Ordep José Serra. São Paulo: Editora Paz e Terra, 1994. 372 p.

LALOU, Frank. Calligraphie hebraïque: initiation. Hamburg: Editions Fleurus, 2004. 80 p.

MAN, John. A História do Alfabeto: como 26 letras transformaram o mundo ocidental. Tradução de Edith Zonenschain. Rio de Janeiro: Ediouro Publicações S. A., 2002. 264 p.

SILVA, S. L.; LANA, S.L.B.; SILVA, S. A. Considerações metodológicas sobre design tipográfico em multiescrita. In: 9o Congresso Brasileiro de Pesquisa e Desenvolvimento em Design 2010, São Paulo. Anais... p. 2233 - 2240. Disponível em: <http://blogs. anhembi.br/congressodesign/anais/consideracoes-metodologicas-sobre-designtipografico-em-multiescrita> Acesso em: 24 mar. 2011. 
SILVA, S.L.; SILVA, S. A. Influências latinas na tipografia grega: análise histórica e abordagem não predatória de projetos multiescrita. Infodesign (SBDI. Online), v. 7, p. 27-39, 2010. Disponível em: <http://www.infodesign.org.br/revista/index.php/ infodesign/article/view/97> Acesso em: 13 fev. 2011.

SILVA, S.L.; SILVA, S. A.; LANA, S.L.B. O design simultâneo e incremental em projetos tipográficos multiescrita. In: 5o CIDI - Congresso Internacional de Design da Informação, 2011, Florianópolis. Anais... 1 CD-ROM.

SILVA, S.L. Incorporando a tipografia cirílica à metodologia do design multiescrita In: 60 CIDI - Congresso Internacional de Design da Informação, 2013, Recife. Anais... p. 14401447. Disponível em: < http://dx.doi.org/10.5151/designpro-CIDI-135 > Acesso em 02 ago. 2014.

TOLEDO, Sivan; ROSENBERG, Zvika. Experience with OpenType font production. 2003. 12 p. TUGboat - The Communications of the TeX Users Group - 24:3, 2003 Disponível em: <http://www.tug.org/TUGboat/Articles/tb24-3/toledo.pdf> Acesso em: 09 out. 2010.

UNICODE, Consortium. The Unicode Standard Version 5.2. 2009. 656 p. Disponível em: $<$ http://www.unicode.org/versions/Unicode5.2.0/UnicodeStandard-5.2.zip>. Acesso em: 22 abr. 2011.

YARDENI, Ada. The book of hebrew script: history, palaeography, script styles, calligraphy \& design. Jerusalem: The British Library \& Oak Knoll Press, 2002. 355 p. 